\title{
Análise de carcinomas epidermóides por meio de radiografia panorâmica e tomografia computadorizada
}

\section{Analysis of squamous cell carcinomas by means of panoramic radiography and computed tomography}

\author{
Amanda Cáceres PEREIRA* \\ Marcelo de Gusmão Paraiso CAVALCANTI** \\ Patrícia dos Santos TOSSATO* \\ Fábio José GUIDA*** \\ Maria Cecília Andrea DUAIK*** \\ Márcia KUROISHI***
}

\begin{abstract}
PEREIRA, A. C.; CAVALCANTI, M. de G. P.; TOSSATO, P. dos S.; GUIDA, F. J.; DUAIK, M. C. A.; KUROISHI, M. Análise de carcinomas epidermóides por meio de radiografia panorâmica e tomografia computadorizada. Pesqui Odontol Bras, v. 15, n. 4, p. 320-326, out./dez. 2001.
\end{abstract}

\begin{abstract}
Este trabalho teve como objetivo correlacionar aspectos radiográficos como, localização e extensão do tumor, infiltração óssea e de tecidos moles e destruição das corticais, obtidos nas radiografias panorâmicas com os encontrados nas tomografias computadorizadas (TCs). Os aspectos radiográficos de 48 pacientes com diagnóstico histopatológico de carcinomas epidermóides, localizados em várias regiões do complexo buco-maxilo-facial, foram analisados por 4 radiologistas. As radiografias panorâmicas e as tomografias computadorizadas foram realizadas nos hospitais e clínicas da Universidade de Iowa (EUA), FUNDECTO - USP e Hospital Universitário da Universidade de São Paulo (SP, Brasil). Como resultados, obtivemos a grande limitação da radiografia panorâmica em determinar a localização e extensão do tumor, com delimitações bastante imprecisas da lesão. Já as TCs ofereceram resultados mais direcionados como: invasão do tumor em direção a estruturas moles adjacentes, extensão da destruição óssea, bem como a profundidade da lesão, que foram confirmados com os achados cirúrgicos. Concluímos que a tomografia computadorizada demonstrou ser uma técnica bastante sensivel na detecção do comprometimento ósseo e do envolvimento de tecidos moles, proporcionando, assim, o auxílio no diagnóstico e no planejamento do tratamento. No entanto, a radiografia panorâmica foi muito pouco sensivel e eficaz, por mostrar apenas margens imprecisas e pouco nítidas da lesão, não avaliando o envolvimento de tecidos moles.
\end{abstract}

UNITERMOS: Carcinoma de células escamosas; Radiografia panorâmica; Tomografia computadorizada por raios X.

\section{INTRODUÇÃO}

Carcinomas epidermóides são os tumores com maior prevalência na cavidade oral, perfazendo $91 \%$ de todas as neoplasias malignas encontradas nesta região ${ }^{17}$. A incidência desta neoplasia na mandíbula é de $12 \%$ a $56 \%$ de acordo com vários estudos ${ }^{2,3,14,22,25,26,27,26}$. Os carcinomas epidermóides são mais freqüentes na mandíbula, ocorrendo duas ou três vezes mais do que na maxila ${ }^{4,11,30}$, podendo atingir várias áreas da cavidade bucal, como: glândulas parótidas e submandibulares, lingua, assoalho bucal, palato, seios maxilares, orofaringe, região retromolar e processo alveolar.

Vários métodos radiográficos são utilizados para determinar a invasão e extensão do carcinoma epidermóide. No estágio inicial da doença, esta pode ser identificada através de um exame rotineiro $^{20,21}$, porém em estágios mais avançados é muito dificil a determinação da lesão em radiografias panorâmicas. O diagnóstico deve ser feito com base em radiografias conjugadas. A tomografia computadorizada (TC) apresenta inúmeros cortes, o que possibilita a interpretação com imagens conjuga$\operatorname{das}^{10,12,13,18,23}$.

\footnotetext{
*Alunas do Curso de Odontologia da USP e de Iniciação Científica PIBIC/CNPq.

**Professor Doutor da Disciplina de Radiologia do Departamento de Estomatologia da Faculdade de Odontologia da USP. Professor Adjunto, Departamento de Radiologia, Faculdade de Medicina, Universidade de Iowa.

*** Médicos Radiologistas do Hospital Universitário da USP.
} 
PEREIRA, A. C.; CAVALCANTI, M. de G. P.; TOSSATO, P. dos S.; GUIDA, F. J.; DUAIK, M. C. A.; KUROISHI, M. Análise de carcinomas epidermóides por meio de radiografia panorâmica e tomografia computadorizada. Pesqui Odontol Bras, v. 15, n. 4, p. 320-326, out./dez. 2001.

A TC nos oferece conjuntos de cortes que possibilitam a interpretação de imagens conjugadas para a determinação de modificações morfológicas resultantes de doenças malignas ou benignas da cavidade oral $^{5}$, assim como alta qualidade de imagens com resoluções anatômicas excelentes e redução dos artefatos. A TC proporciona resultados mais direcionados como grau de infiltração do tumor, envolvimento das corticais ósseas, sendo possível a detecção da localização primária do tumor $^{28}$.

Muitos trabalhos ${ }^{9,17}$ puderam confirmar através dos achados histopatológicos, o envolvimento ósseo mostrado na TC, conferindo grande confiabilidade e especificidade a este método, com uma taxa de falso positivo inferior a $8,3 \%{ }^{8}$. Por este motivo e pela determinação total da extensão da invasão tumoral, a TC tem sido a técnica recomendada como modalidade primária de diagnóstico de neoplasias malignas $^{6,16}$.

O objetivo deste trabalho foi correlacionar os aspectos radiográficos como: localização primária do tumor, expansão e destruição das corticais e grau de infiltração do tumor com envolvimento de tecidos moles, nas tomografias computadorizadas, destacando-se as vantagens destas perante as radiografias panorâmicas em proporcionar informações essenciais ao diagnóstico, tratamento e prognóstico do carcinoma epidermóide.

\section{MATERIAL E MÉTODOS}

Foram comparadas as radiografias panorâmicas e tomografias computadorizadas (TCs) de 48 pacientes com carcinomas epidermóides na região de cabeça e pescoço, como língua, assoalho bucal, palato duro, glândulas parótidas e submandibulares e seios maxilares. Esses pacientes foram previamente submetidos à TC (X/Press Toshiba America Systems Inc.) com 120 kVp e 200 mA, e cortes de $3 \mathrm{~mm}$ de espessura, $3 \mathrm{~mm}$ de incremento de mesa e $3 \mathrm{~mm}$ de intervalo de reconstrução com filtro $\mathrm{FC} 20$ e receberam contraste intravenoso $\left(150 \mathrm{ml}\right.$ de Conray $60^{\circledR}$ ) para ajudar na visualização de tecidos moles envolvidos.

As TCs e as radiografias panorâmicas foram realizadas na University of Iowa Hospital and Clinics, na Fundação de Desenvolvimento Científico e Tecnológico de Odontologia (FUNDECTO) e no Hospital Universitário da Universidade de São Paulo, Brasil. Tanto as radiografias panorâmicas quanto as TCs foram analisadas por 4 radiologis- tas, 3 médicos radiologistas e 1 cirurgião-dentista, a fim de determinar a localização e extensão do tumor, destruição óssea, e envolvimento de tecidos moles adjacentes.

As imagens das TCs e das radiografias panorâmicas foram analisadas levando-se em consideração a sensibilidade de cada uma dessas técnicas radiográficas. Algumas características das lesões dos carcinomas epidermóides como, localização primária do tumor, destruição das corticais ósseas e extensão e envolvimento de tecido mole adjacente, foram estabelecidas como critérios para o estudo qualitativo das radiografias panorâmicas e das TCs.

A sensibilidade relaciona-se com os falsos negativos obtidos nas TCs e nas radiografias panorâmicas, e por isso, foi possivel o seu cálculo. Porém as especificidades destes dois métodos não foram comparadas, visto que não possuíamos nenhum falso positivo de carcinoma epidermóide, ou seja, todas as radiografias panorâmicas e TCs analisadas pertenciam a pacientes com diagnóstico de carcinoma epidermóide, confirmados histopatologicamente.

\section{RESULTADOS}

Os carcinomas epidermóides tinham como local de origem a lingua (13 casos), palato duro (7 casos), assoalho bucal (11 casos), glândula parótida (6 casos), glândula submandibular (6 casos) e seios maxilares (5 casos) (Tabela 1 ).

Das 48 radiografias panorâmicas analisadas, em apenas 4 radiografias foi possivel visualizar a localização primária dos carcinomas, que acometiam o palato duro, glândula parótida (estendendo-se para a região intra-óssea) e seios maxilares (2 casos), contrastando com 42 tomografias computadorizadas, em que a localização do tumor também foi feita em estruturas de tecidos moles. As sensibilidades da radiografia panorâmica e da TC na detecção da localização primária do tumor foram de 8,3\% (44 falsos negativos) e 87,5\% (6 falsos negativos), respectivamente.

A sensibilidade da radiografia panorâmica levando-se em consideração o critério destruição das corticais ósseas foi de $51,7 \%$, com 15 falsos negativos, excluindo-se os 19 casos em que o tumor localizava-se em tecidos moles (lingua e glândulas submandibulares) e não envolviam corticais ósseas. A sensibilidade da TC foi de 100\%.

Analisando-se o critério extensão no envolvi- 
PEREIRA, A. C.; CAVALCANTI, M. de G. P.; TOSSATO, P. dos S.; GUIDA, F. J.; DUAIK, M. C. A.; KUROISHI, M. Análise de carcinomas epidermóides por meio de radiografia panorâmica e tomografia computadorizada. Pesqui Odontol Bras, v. 15, n. 4, p. 320-326, out./dez. 2001.

TABELA 1 - Estudo comparativo entre os achados da radiografia panorâmica (Pan.) e da tomografia computadorizada (TC) quanto à localização, destruição das corticais e envolvimento do tecido mole adjacente nas lesões de carcinomas epidermóides.

\begin{tabular}{|c|c|c|c|c|c|c|c|}
\hline \multirow{2}{*}{ Região } & \multirow{2}{*}{ Total } & \multicolumn{2}{|c|}{ Localização do tumor } & \multicolumn{2}{|c|}{ Destruição das corticais } & \multicolumn{2}{|c|}{ Envolvimento do tecido mole } \\
\hline & & Pan. & $\mathrm{TC}$ & Pan. & $\mathrm{TC}$ & Pan. & $\mathrm{TC}$ \\
\hline Língua & 13 & 0 & 13 & - & - & 0 & 13 \\
\hline Palato duro & 7 & 1 & 6 & 3 & 7 & 0 & 7 \\
\hline Assoalho bucal & 11 & 0 & 11 & 2 & 11 & 0 & 11 \\
\hline Glândula parótida & 6 & 1 & 3 & $2 *$ & 2 & 0 & 6 \\
\hline Glândula submandibular & 6 & 0 & 4 & - & - & 0 & 6 \\
\hline Seio maxilar & 5 & 2 & 5 & 3 & 5 & 0 & 5 \\
\hline
\end{tabular}

*Intra-ósseo.

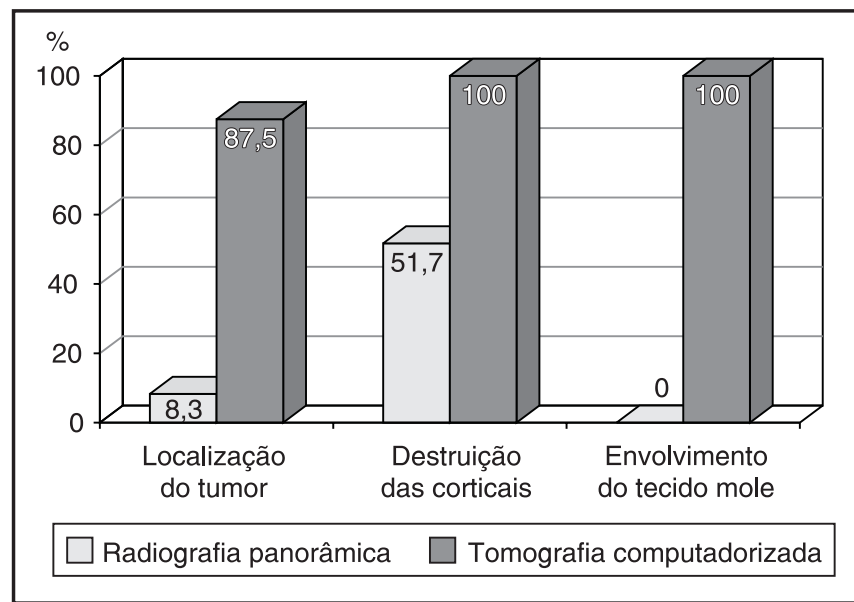

GRÁFICO 1 - Comparação entre as sensibilidades da radiografia panorâmica e da tomografia computadorizada.

mento de tecidos moles adjacentes, a radiografia panorâmica apresentou $0 \%$ de sensibilidade, o que representa uma correlação negativa entre panorâmica e achado cirúrgico, com 48 falsos negativos. No entanto, a TC obteve sensibilidade de 100\%, com excelente correlação com os achados cirúrgicos, sem falsos negativos (Gráfico 1).

\section{RELATO DE CASO CLÍNICO}

J. S., 60 anos, melanodermo, do sexo masculino, que apresentava sinais de tumefação, pequeno inchaço, proporcionando assimetria facial e trismo discreto, foi encaminhado ao Serviço de Radiologia da FUNDECTO em abril de 1999 para realização da radiografia panorâmica. Após 15 dias, o paciente foi submetido à TC no Hospital Universitário da USP. O exame histopatológico foi feito, com diag- nóstico de carcinoma epidermóide originário da glândula parótida do lado esquerdo.

A radiografia panorâmica mostrou uma lesão radiolúcida pouco delimitada e envolvendo parte do ramo ascendente da mandíbula do lado esquerdo (Figura 1).

Os achados da TC mostraram a invasão nítida das corticais ósseas, com grande destruição do ramo ascendente esquerdo da mandíbula, envolvimento da base do crânio (região do forame magno), osso esfenóide e parte petrosa do osso temporal. Constatou-se também a invasão nos tecidos musculares localizados na orofaringe, envolvendo os músculos pterigóideo medial e lateral esquerdos, masseter e bucinador esquerdos e parte do assoalho bucal, não envolvendo a região submandibular. Detectou-se, através da TC, a origem do tumor correlacionando-a com a região parotídea, bem como sua direção de expansão para medial e inferior (Figura 2). Foi estimada, com a TC, a profundidade da lesão que foi de $90 \mathrm{~mm}$. A lesão localizava-se na região facial do lado esquerdo do indivíduo e a TC revelou a invasão dos músculos, profundidade e nitidez quanto ao limite da lesão na região da mandíbula e nos outros ossos envolvidos.

Subseqüentemente, esse paciente recebeu radioterapia para um posterior planejamento cirúrgico.

\section{DISCUSSÃO}

Aproximadamente $91 \%$ dos carcinomas na cavidade oral são carcinomas epidermóides ${ }^{7}$. Três fatores são importantes no planejamento do trata- 
PEREIRA, A. C.; CAVALCANTI, M. de G. P.; TOSSATO, P. dos S.; GUIDA, F. J.; DUAIK, M. C. A.; KUROISHI, M. Análise de carcinomas epidermóides por meio de radiografia panorâmica e tomografia computadorizada. Pesqui Odontol Bras, v. 15, n. 4, p. 320-326, out./dez. 2001.

mento desta neoplasia: presença e extensão do tumor; avaliação do envolvimento das estruturas adjacentes, tanto ósseas quanto de tecidos moles, para que a preservação da função após a ressecção possa ser estimada ou garantida; e consistência da massa tumoral ${ }^{14}$.

Os sintomas dos pacientes estudados, assim como em vários estudos ${ }^{20,21}$, apareceram no curso mais avançado da doença: trismo, inchaço, dores semelhantes à nevralgia, dificultando o diagnóstico precoce desta neoplasia. Além da destruição cortical do osso e infiltração nos músculos mastigatórios, ocasionalmente a lesão se desenvolve ao longo da divisão do nervo trigeminal, podendo invadir o interior do crânio ${ }^{8,19,22}$, o que pôde ser observado em nosso relato de caso clínico.

Muitos estudos que avaliam a invasão mandibular pelos carcinomas epidermóides obtiveram indices de falsos negativos e falsos positivos. A avaliação clínica, embora estime a profundidade da infiltração tumoral em direção à mandíbula ou dentro da própria mandíbula, é muito pouco sensível $(39 \%)^{29}$, podendo fornecer dados não compatíveis com a extensão real do envolvimento mandibular pelo carcinoma, devido à inflamação que pode prejudicar a visualização das margens do tumor $^{1}$.

Em nosso trabalho, analisamos, através de radiografias panorâmicas e tomografias computadorizadas, a localização dos carcinomas epidermóides, destruição das corticais ósseas e envolvimento de estruturas de tecidos moles.

Em estudos qualitativos de lesões mandibulares provocadas pelos carcinomas epidermóides, as radiografias panorâmicas têm tido baixos índices de sensibilidade, entre $5 \%$ a $7 \%{ }^{15}$. Em nosso trabalho, as sensibilidades na detecção da localização primária do tumor, destruição das corticais e envolvimento de tecidos moles foram de 8,3\% (44 falsos negativos), $51,7 \%$ (15 falsos negativos) e $0 \%$ (48 falsos negativos), respectivamente. Estas altas taxas de falsos negativos devem-se à superposição de estruturas ósseas e ausência na relação da lesão com o tecido mole adjacente, tornando a radiografia panorâmica uma técnica pouco sensivel e incapaz de fornecer dados essenciais ao diagnóstico, tratamento e prognóstico dos carcinomas. Segundo Van den BREKEL et al. ${ }^{29}$ (1998), 30\% dos casos com infiltração tumoral não foram evidenciados na radiografia panorâmica, e outros apresentaram limites imprecisos, isto é devido ao grande número de sobreposições de estruturas que dificultam a visualização do tumor.

Assim como afirma KALAVREZOS et al. ${ }^{17}$ (1996), consideramos a TC como um método muito sensivel na avaliação primária dos carcinomas epidermóides (tamanho, localização e expansão para tecidos moles). A sensibilidade da TC na detecção da localização primária da neoplasia foi de $87,5 \%$ com 6 falsos negativos, em que não foi possível certificar o local exato da origem tumoral, porém verificaram-se alterações em tecidos ósseos e moles. A sensibilidade da TC, quando consideramos os critérios destruição das corticais ósseas e invasão de tecidos moles adjacentes, foi de $100 \%$, sem falsos negativos, como em muitos trabalhos que mostraram altos índices de sensibilidade da TC quanto ao envolvimento de estruturas adjacentes e outras alterações provocadas pelo carcinoma ${ }^{8,24,28,29}$.

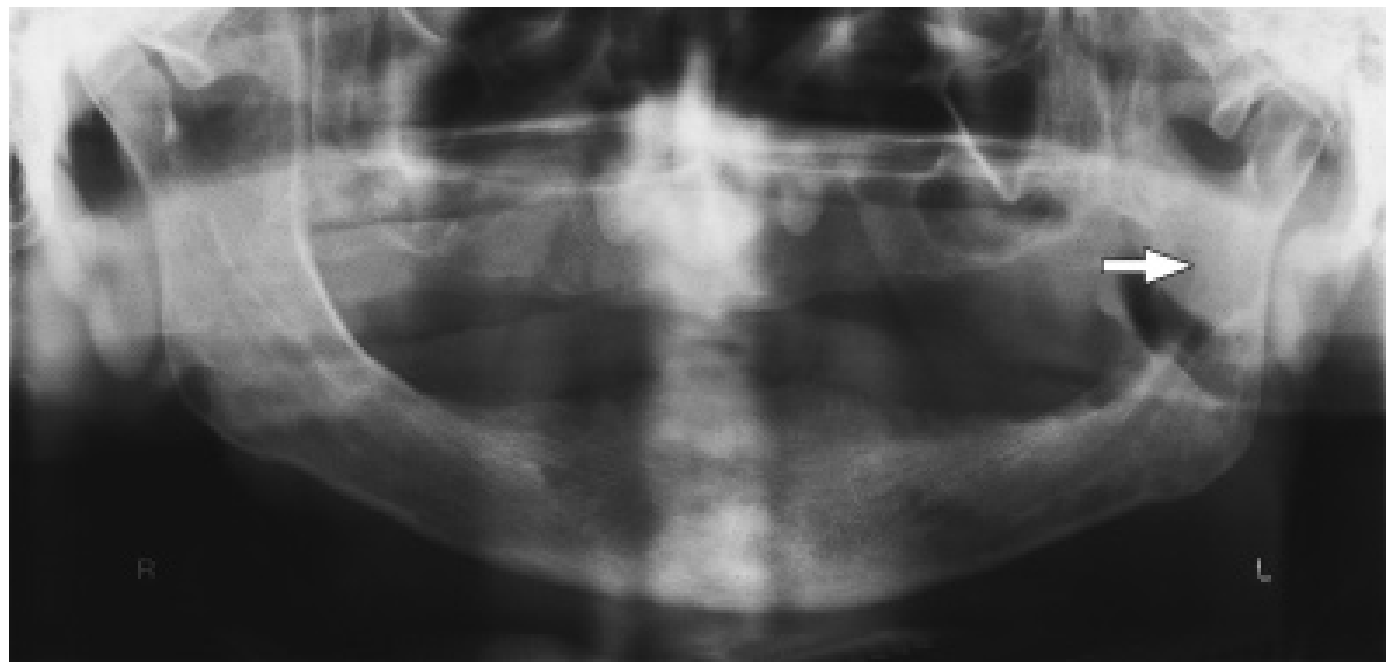

FIGURA 1 - Radiografia panorâmica. Lesão pouco nitida e de margens imprecisas, localizada no ramo ascendente da mandíbula, do lado esquerdo, com destruição óssea (seta). 
PEREIRA, A. C.; CAVALCANTI, M. de G. P.; TOSSATO, P. dos S.; GUIDA, F. J.; DUAIK, M. C. A.; KUROISHI, M. Análise de carcinomas epidermóides por meio de radiografia panorâmica e tomografia computadorizada. Pesqui Odontol Bras, v. 15, n. 4, p. 320-326, out./dez. 2001.
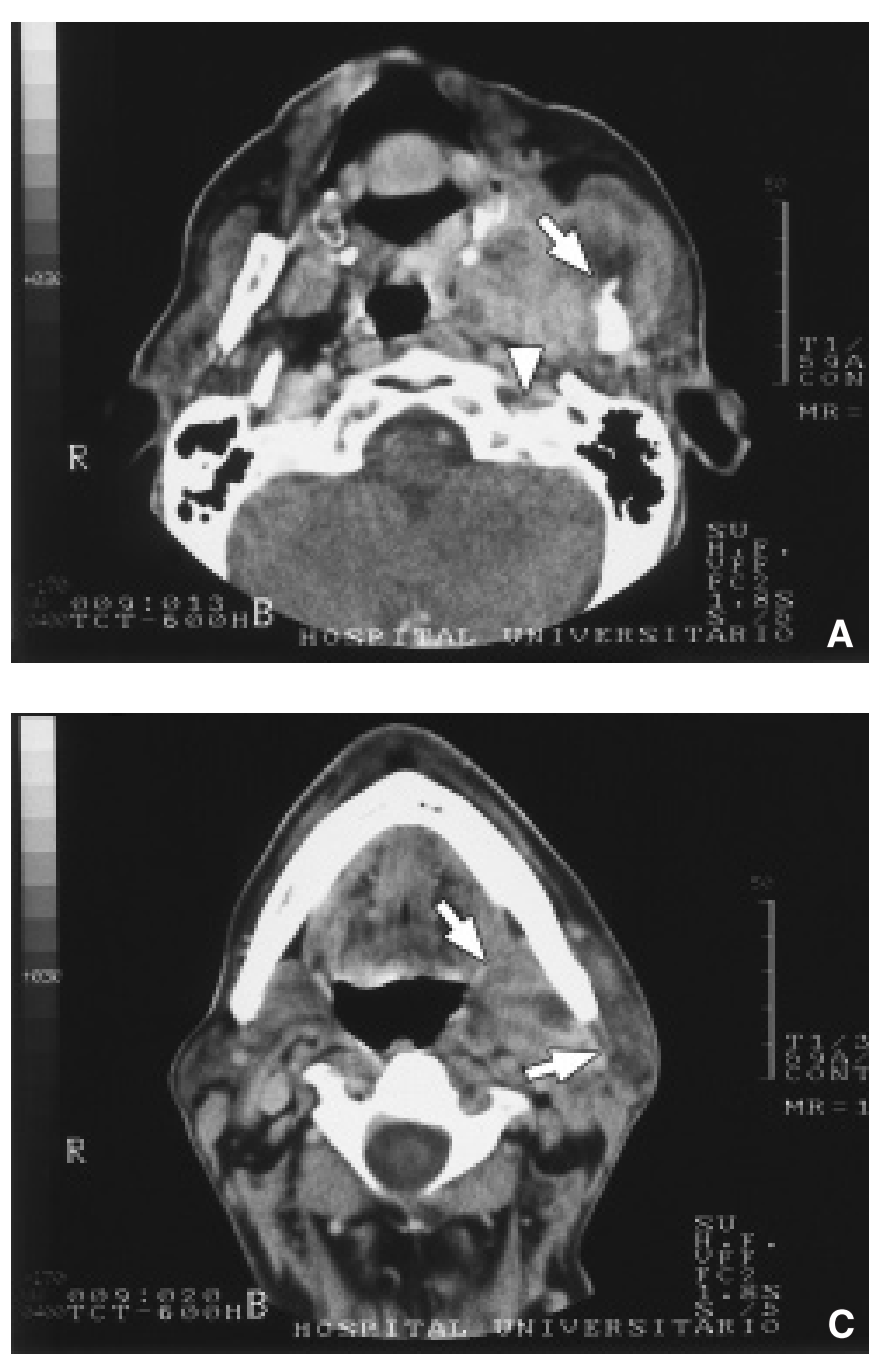

Contrastando com os trabalhos de TSUE et al. ${ }^{28}$ (1986) e SHAHA et $a l .{ }^{24}$ (1991) que relatam que a TC não avalia precisamente e com eficiência a destruição cortical, apresentando 64\% de sensibilidade, nosso estudo e de diversos autores afirmam que a TC tem sido muito sensivel quanto à avaliação da destruição cortical ${ }^{2,8}$, com $100 \%$ de sensibilidade mostrada em nosso estudo. Esta diferença nas sensibilidades da TC deve-se, particularmente, à técnica da obtenção das imagens, visto que a espessura de corte é variável e pode detalhar muito ou pouco a área neoplásica, e nestes estudos que contradizem o nosso a espessura de corte da TC foi de $6 \mathrm{~mm}$, o que, dependendo da região, pode proporcionar pouco detalhamento, dificultando a detecção precisa da infiltração tumoral. Porém concordamos com estes autores quando afirmam que para se realizar estudos de alta resolução são ne-

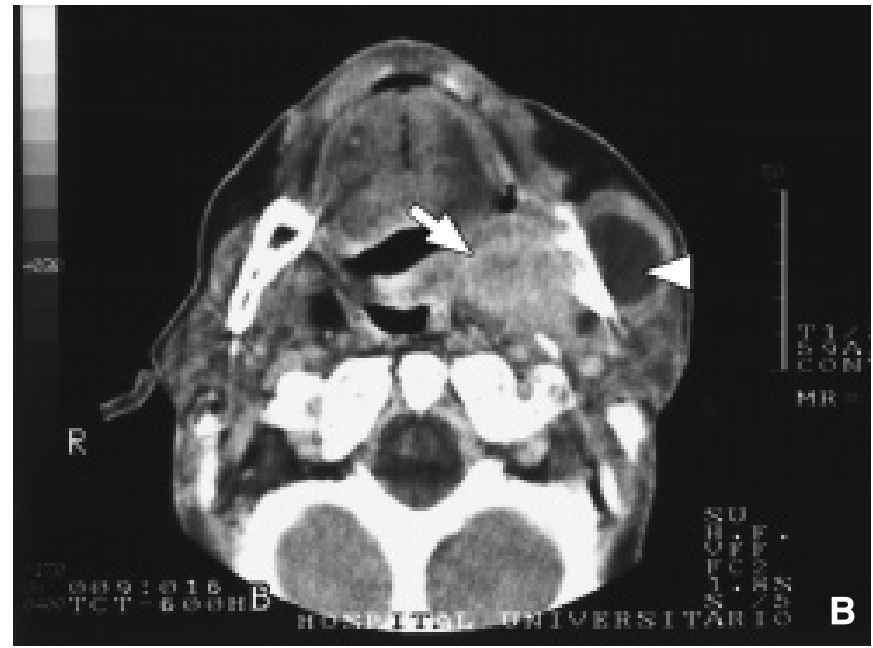

FIGURA 2 - Tomografia computadorizada.

A: destruição do ramo ascendente da mandíbula do lado esquerdo (seta); envolvimento da base do crânio (cabeça de seta). B: tumor envolvendo ramo ascendente da mandíbula em direção à orofaringe (seta); presença de abscesso do lado esquerdo (cabeça de seta) e extensão para os músculos pterigóideo lateral, medial e masseter.

C: envolvimento da glândula parótida e expansão da neoplasia (setas).

cessários cortes de 2 a $3 \mathrm{~mm}$ de espessura que fornecerá um maior detalhamento das estruturas, aumentando a sensibilidade da TC. A especificidade da TC, de acordo com muitos autores, é bastante alta, com baixas taxas de falsos positivos.

A TC tem sido o exame de escolha no diagnóstico e plano de tratamento de carcinomas epidermóides devido à excelente descrição de estruturas ósseas e à ótima definição dos tecidos moles envolvidos, fornecendo-nos sensibilidade superior à da radiografia panorâmica.

\section{CONCLUSÕES}

Concluímos que a tomografia computadorizada mostrou ser uma técnica bastante sensivel demonstrando mais claramente a localização do tumor, destruição das corticais ósseas e envolvimento de estruturas moles adjacentes. Além disso, 
PEREIRA, A. C.; CAVALCANTI, M. de G. P.; TOSSATO, P. dos S.; GUIDA, F. J.; DUAIK, M. C. A.; KUROISHI, M. Análise de carcinomas epidermóides por meio de radiografia panorâmica e tomografia computadorizada. Pesqui Odontol Bras, v. 15, n. 4, p. 320-326, out./dez. 2001.

demonstra excelente correlação com os achados cirúrgicos, auxiliando no diagnóstico e no planejamento do tratamento de carcinomas epidermóides. Entretanto, a radiografia panorâmica, apesar de ser um exame auxiliar no diagnóstico inicial, demonstrou apenas delimitações imprecisas e pouco nítidas da lesão. Isto demonstrou uma baixa sensibilidade, tornando inviável o uso do método tan- to para o diagnóstico quanto para o planejamento do tratamento destas lesões.

\section{AGRADECIMENTOS}

CNPq (Bolsa de Iniciação Científica, nº 677, Amanda Cáceres Pereira).

CNPq (Projeto $n^{\circ}$ 520425/99-5, Prof. Dr. Marcelo de G. P. Cavalcanti).

PEREIRA, A. C.; CAVAlCANTI, M. de G. P.; TOSSATO, P. dos S.; GUIDA, F. J.; DUAIK, M. C. A.; KUROISHI, M. E. Analysis of squamous cell carcinomas by means of panoramic radiography and computed tomography. Pesqui Odontol Bras, v. 15, n. 4, p. 320-326, out./dez. 2001.

The purpose of this work was to compare radiographic findings, such as localization and extension of tumors toward the bone and soft tissues, in panoramic radiography and computed tomography (CT). Four radiologists assessed the radiographic findings of 48 patients with the histopathological diagnosis of squamous cell carcinoma in different sites of the maxillofacial region. Panoramic radiographs and computed tomographs were obtained at the University of Iowa Hospitals and Clinics, at FUNDECTO - USP and at the hospital of the University of São Paulo (USP). We observed a considerable limitation of the panoramic radiography in determining the localization and extension of tumors, since it revealed unclear delimitations. Regarding CT, better results were obtained: it was possible to observe the invasion of the tumor toward adjacent soft tissues, as well as the extension of bone destruction and the depth of the lesion, which were confirmed by surgical findings. We concluded that computed tomography demonstrated to be a sensitive radiographic technique for the detection of the involvement of bone and soft tissues, contributing for a more precise diagnosis, surgical planning and intervention. On the other hand, panoramic radiography was considered less sensitive and less efficient than CT, since it shows only unclear borders of the lesions and is not able to assess the involvement of soft tissues.

UNITERMS: Carcinoma, squamous cell; Radiography, panoramic; Tomography, X-ray computed.

\section{REFERÊNCIAS BIBLIOGRÁFICAS}

1. ATOR, G. A.; ABEMAYOR, E. A.; LUFKIN, R. B. et al. Evaluation of mandibular tumor invasion with magnetic resonance imaging. Arch Otolaryngol Head Neck Surg, v. 116, p. 454-459, 1990.

2. BAHADUR, S. Mandibular involvement in oral cancer. $\mathbf{J}$ Laryngol Otol, v. 104, p. 968-971, 1990.

3. BARTTELBORT, S. W.; BAHN, S. L.; ARIYAN, S. Rim mandibulectomy for cancer of the oral cavity. Am J Surg, v. 154, p. 423-428, 1987.

4. BROWAND, B. C.; WALDRON, C. A. Central mucoepidermoid tumors of the jaws: report of nine cases and review of the literature. Oral Surg Oral Med Oral Pathol, v. 40, p. 631-643, 1995.

5. CAVALCANTI, M. G. P.; RUPRECHT, A.; QUETS, J. Evaluation of maxillofacial fibrosarcoma using computer graphics and spiral computed tomography. Dentomaxillofac Radiol, v. 28, p. 145-151, 1999.

6. CAVALCANTI, M. G. P.; VANNIER, M. W. The role of three-dimensional spiral computed tomography in oral metastases. Dentomaxillofac Radiol, v. 27, p. 203-209, 1998.

7. CHRISTIANSON, R.; LUFKIN, R. B.; ABEMAYER, E.; HANAFEE, W. MRI of mandible. Surg Radiol Anat, v. 11, p. 163-169, 1989.

8. CLOSE, L. G.; BURNS, D. K.; MERKEL, M.; SCHAEFER, S. D. Computed tomography in the assessment of mandi- bular invasion by intraoral carcinoma. Ann Otol Rhinol Laryngol, v. 95, p. 383-388, 1986.

9. EIICHIRO, A.; SATORU, O.; KOICHI, Y. et al. Central squamous cell carcinoma of the mandible. Oral Surg Oral Med Oral Pathol, v. 77, p. 541-548, 1994.

10. EISELE, D. W.; RICHTSMEIER, W. J.; GRAYBEL, J. C. et al. Three-dimensional models for head and neck tumor treatment planning. Laryngoscope, v. 104, p. 433-439, 1994.

11. EZSIAS, A.; SUGAR, A. W.; MILLING, M. A.; ASHLEY, K. F. Central mucoepidermoid carcinoma in a child. J Maxillofac Surg, v. 52, p. 512-515, 1994.

12. FAGELMAN, D.; HUANG, A. B. Prospective evaluations of lesion of the mandible and maxilla: findings on multiplanar and three-dimensional CT. Am J Roentgenol, v. 163, p. 693-698, 1994.

13. FRIEDMAN, M.; MAFEE, M.; RAY, C.; VENKATESAN, T. K. Three dimensional imaging for evaluation of head and neck tumors. Arch Otolaryngol Head Neck Surg, v. 119, p. 601-607, 1993.

14. GILBERT, S.; TZADIK, A.; LEONARD, G.; FARMINGTON, C. T. Mandibular involvement by oral squamous cell carcinoma. Laryngoscope, v. 96, p. 96-101, 1986.

15. INAGAKI, M.; YUASA, K.; NAGAYAMA, E. et al. Mucoepidermoid carcinoma in the mandible - findings of panoramic radiographic and computed tomography. Oral Surg Oral Med Oral Pathol Oral Radiol Endod, v. 85, p. 613-618, 1998. 
PEREIRA, A. C.; CAVAlCANTI, M. de G. P.; TOSSATO, P. dos S.; GUIDA, F. J.; DUAIK, M. C. A.; KUROISHI, M. Análise de carcinomas epidermóides por meio de radiografia panorâmica e tomografia computadorizada. Pesqui Odontol Bras, v. 15, n. 4, p. 320-326, out./dez. 2001.

16. JACOB, B.; ANA, E.; YOAV, P. T. et al. DentaCT for evaluating mandibular and maxillary invasion in cancer of the oral cavity. Ann Otol Rhinol Laryngol, v. 105, p. 431-437, 1996.

17. KALAVREZOS, N. D.; GRÄTZ, K. W.; SAILER, H. F.; STAHEL, W. A. Correlation of imaging and clinical features in the assessment of mandibular invasion of oral carcinomas. Int J Oral Maxillofac Surg, v. 25, p. 439-445, 1996.

18. MARSH, J. L.; VANNIER, M. W.; STEVEN, W. G. Surface recontructions from computerized tomographic scans for evaluation of malignant skull destruction. Am J Surg, v. 148, p. 530-533, 1984.

19. NAGANAWA, Y.; HINOSHITA, M.; HASHIMOTO, O. et al. A case of central carcinoma of the mandible with invasion along the mandibular nerve. Jpn J Oral Maxillofac Surg, v. 27, p. 1090-1094, 1981.

20. NOLAN, R.; WOOD, N. K. Central squamous cell carcinoma of the mandible: report of a case. J Oral Surg, v. 34, p. 260-264, 1976.

21. OTHAKE, K.; YOKOBAYASHI, Y.; SHINGAKI, S. et al. Central carcinoma of the jaw: a survey of 28 cases in the Japanese literature. J Craniomaxillofac Surg, v. 17, p. 155-161, 1989.

22. PANAGOPOULOS, A. P. Bone involvement in maxillofacial cancer. Am J Surg, v. 98, p. 898-903, 1959.

23. RAY Jr., C. E.; MAFEE, M. F.; FREEDMAN, M.; TAHMORESSI, C. N. Applications of three-dimensional CT ima- ging in head and neck pathology. Radiol Clin North Am, v. 31, p. 181-194, 1993.

24. SHAHA, A. R. Preoperative evaluation of the mandible in patients with carcinoma of the floor of mouth. Head Neck, v. 13, p. 398-402, 1991.

25. SLAUGHTER, D. P.; ROESER, E. N.; SMEJKAL, W. F. Excision of the mandible for neoplastic disease. Surgery, v. 26, p. 507-522, 1949.

26. SPIRO, R. H.; STRONG, E. W. Epidermoid carcinoma of the mobile tongue: treatment by partial glossectomy alone. Am J Surg, v. 122, p. 707-710, 1971.

27. TOTSUKA, Y.; USUI, Y.; TEI, K. et al. Mandibular involvement by squamous cell carcinoma of the alveolus: analysis and comparative study of histologic and radiologic features. Head Neck, v. 48, p. 40-50, 1990.

28. TSUE, T. T.; McCULLOTH, M. T.; GIROD, D. A.; COUPER, D. J.; WEYMULLER, E. A.; GLENN, M. G. Predictors of carcinomatous invasion of the mandible. Head Neck Surg, v. 16, p. 116-126, 1986.

29. VAN DEN BREKEL, M. W. M.; RUNNE, R. W.; SMEELE, L. E. et al. Assessment of tumor invasion into the mandible: the value of different imaging techniques. Eur Radiol, v. 8, p. 1552-1557, 1998.

30. WALDRON, C. A.; KOH, M. L. Central mucoepidermoid carcinoma of the jaws: report of four cases with analysis of the literature and discussion of the relationship to mucoepidermoid, sialodontogenic, and glandular odontogenic cysts. J Oral Maxillofac Surg, v. 48, p. 871-877, 1990.

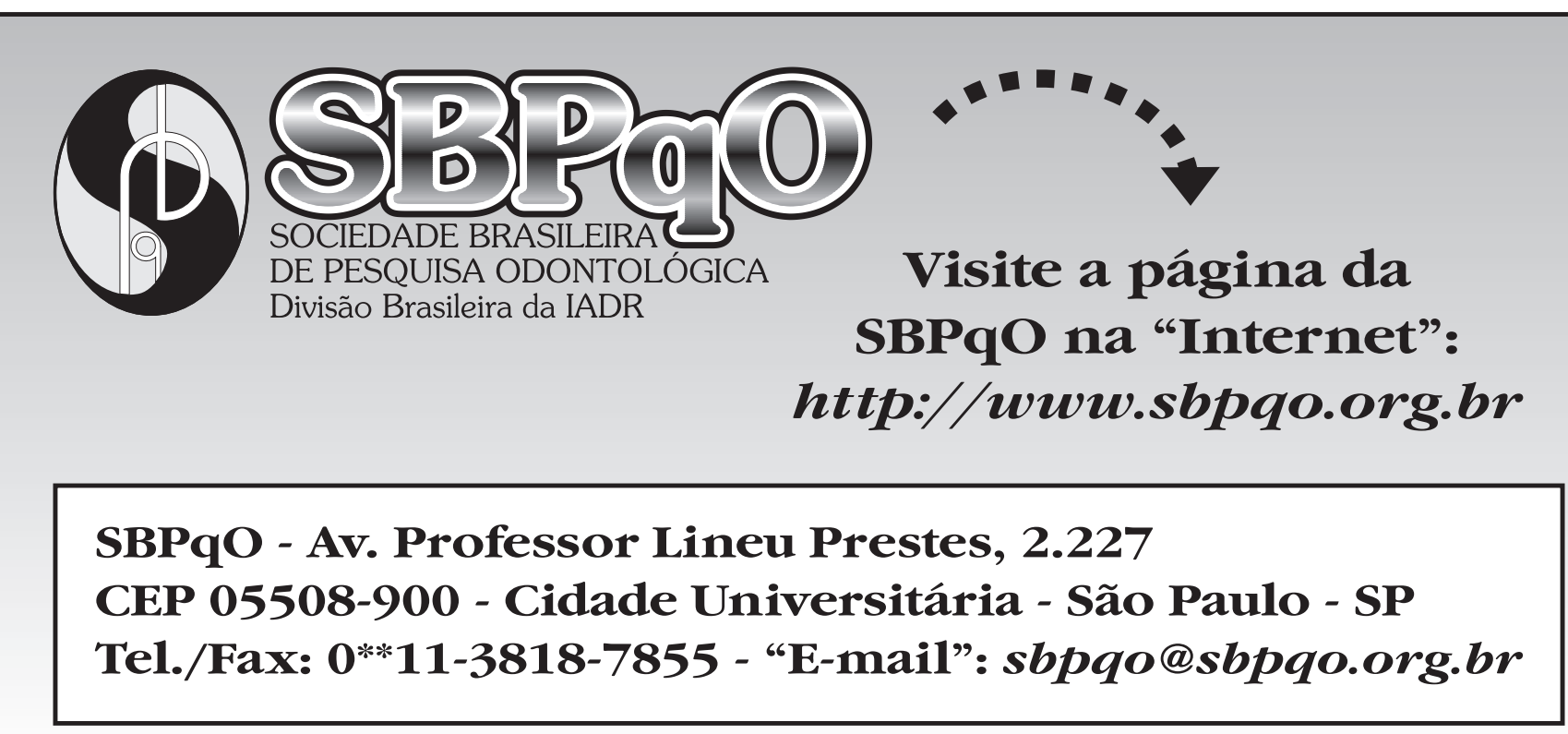

